\title{
Magnification Endoscopy and Chromoendoscopy in Evaluation of Specialized Intestinal Metaplasia in Barrett's Esophagus
}

\author{
Justyna Wasielica-Berger • Andrzej Baniukiewicz • \\ Eugeniusz Wroblewski • Adam Chwiesko • \\ Andrzej Dabrowski
}

Received: 29 August 2010/Accepted: 22 December 2010/Published online: 12 January 2011

(C) The Author(s) 2011. This article is published with open access at Springerlink.com

\begin{abstract}
Background Specialized intestinal metaplasia (SIM) in Barrett's esophagus is a risk factor of esophageal adenocarcinoma. It often occurs focally and cannot be distinguished from surrounding columnar epithelium with conventional endoscopy.

Aims The purpose of this study was evaluation of methylene blue (MB) staining and magnification endoscopy with comparison of pit-pattern classifications according to Endo and Guelrud, in detection of SIM in Barrett's esophagus.

Methods Twenty-five patients, aged 33-77 years (average 57 years), with displacement of $\mathrm{Z}$ line were prospectively enrolled and underwent gastroscopy with the use of magnification up to 115 times (Olympus GIF Q160Z). Biopsy for histopathologic examination was taken from sites stained with $\mathrm{MB}$ and/or places with particular pit patterns. A control group consisted of ten patients with normal gastro-esophageal junction.
\end{abstract}

J. Wasielica-Berger $(\bowtie) \cdot$ A. Baniukiewicz · E. Wroblewski .

A. Chwiesko - A. Dabrowski

Department of Gastroenterology and Internal Medicine,

Medical University of Bialystok, Ul. Sklodowskiej 24a,

15-276 Bialystok, Poland

e-mail: jabw@box43.pl

A. Baniukiewicz

e-mail: banka@umwb.edu.pl

E. Wroblewski

e-mail: Gienekw@op.pl

A. Chwiesko

e-mail: adas76@piasta.pl

A. Dabrowski

e-mail: adabrows@umwb.edu.pl
Results SIM was proved in nine patients, and significantly more frequently in patients with hiatal hernia and Barrett's segment longer than $3 \mathrm{~cm}$. Round or thin linear pit patterns according to Guelrud's and small round and straight pit patterns according to Endo's classification were coupled with columnar epithelium. SIM was associated with deep linear and foveolar pit patterns in Guelrud's classification. Other pit patterns were less characteristic. Both classifications had high sensitivity (Endo's $85.7 \%$, Guelrud's $92.8 \%$ ) but poor specificity (respectively, 21.15 and $28.4 \%$ ) in detection of SIM. Sensitivity and specificity of MB staining were, respectively, 71.4 and $40.6 \%$.

Conclusions Despite existing association between mucosal surface structure and histology, we find no convincing data indicating that pit-pattern evaluation may replace multiple biopsies taken according to recommendations from Seattle for detection of SIM in Barrett's esophagus.

Keywords Magnification endoscopy ·

Barrett's esophagus · Pit pattern - Methylene blue .

Intestinal metaplasia

\section{Introduction}

Barrett's esophagus (BE) is a premalignant condition caused by chronic gastroesophageal reflux. According to Montreal consensus from 2006, it is characterized as replacement of the squamous epithelium in the distal esophagus by columnar epithelium (gastric metaplasia), irrespective of the presence of specialized intestinal metaplasia (SIM) [1]. Still, SIM is the most important identified risk factor of esophageal adenocarcinoma. During the last 30 years the incidence of esophageal 
adenocarcinoma has increased five to six times and nowadays it constitutes half of all esophageal cancers [2, 3]. Guidelines of the American College of Gastroenterology state that every patient with gastroesophageal reflux symptoms should at least once in a lifetime be referred for Barrett's esophagus screening endoscopy [4]. Patients with SIM in columnar-lined esophagus are currently advised to undergo a periodic endoscopic surveillance to detect progression to dysplasia at an early, potentially curable stage.

Although gastric metaplasia in esophagus is easily visible as a displacement of $\mathrm{Z}$ line over the upper limit of gastric folds, it is difficult to discern SIM; what is more, it usually occurs focally. According to Seattle protocol, to identify presence of SIM and dysplasia, four-quadrant biopsies should be obtained at 2-cm intervals along the length of Barrett's esophagus [4]. The major disadvantages of this method are the need for multiple biopsies, random choice of biopsy places and high cost. A technique improving mucosal visualization and differentiating SIM and dysplasia from columnar epithelium during endoscopy would provide more accurate biopsy, reduce the number of biopsies and in the future even eliminate biopsies.

New techniques such as chromoendoscopy and magnification endoscopy have been tried to improve recognition of SIM. Chromoendoscopy involves the use of dyes sprayed over mucosa. Methylene blue (MB) stains actively absorbing cells such as those of intestinal epithelium and intestinal metaplasia [5]. Sensitivity and specificity of MB staining for SIM detection in Barrett's esophagus is still under discussion [6].

Endoscopes with the function of optical magnification are equipped with the system of movable lenses which enable gradual magnification of the observed field from 1.5 to 150 times [7]. Contrary to electronic magnification, optical magnification enhances not only the size of the image, but also the number of visible details.

After magnification a characteristic relief called pit pattern is visible on the surface of esophageal epithelium below $\mathrm{Z}$ line. Most widely known classifications of esophageal pit patterns, together with connection to histology, were described by Endo et al. in 2002 [8] and by Guelrud et al. in 2004 [9]. Apart from magnification, Endo used methylene blue staining in his study. Guelrud evaluated pit patterns after enhancing its visibility by spraying acetic acid, which caused temporary protein denaturation and loss of transparency of mucosa. Neither of those two studies examined pit patterns below the $\mathrm{Z}$ line in the control group. The usefulness of those classifications, such as predicting the presence of SIM on the base of structure of mucosal surface demands further evaluation. Moreover, pit patterns have never been defined simultaneously in both classifications.
The aim of the present study was the evaluation of magnification endoscopy together with methylene blue chromoendoscopy for detecting intestinal metaplasia in Barrett's esophagus and comparison of Endo's and Guelrud's classifications.

\section{Methods}

Patients with previously diagnosed SIM in Barrrett's esophagus and patients referred for endoscopy to the Department of Gastroenterology and Internal Medicine of the Medical University in Bialystok to evaluate the presence of SIM in Barrett's esophagus were prospectively enrolled into the study. After four weeks of treatment with proton pump inhibitors, patients underwent endoscopy of the upper gastrointestinal tract with the detailed examination of columnar mucosa in esophagus using optical magnification up to 115 times (Olympus GIF Q160Z). The endoscopist was not informed about patients' previous diagnosis of SIM. Circumferential and maximal extension of columnar mucosa in esophagus was estimated according to the Prague consensus [10]. Mucus was removed by the $10 \%$ solution of acetylocysteine instillation. The magnified images were analyzed with respect to pit patterns, which were simultaneously classified both in Endo's and Guelrud's scale. Then, $0.5 \%$ solution of methylene blue was sprayed over columnar mucosa. The excess of dye was flushed away with $50 \mathrm{ml}$ of water after $1 \mathrm{~min}$. Biopsy specimens for the histopathologic examination were taken from the regions stained with $\mathrm{MB}$ and/or sites with pit patterns most often connected with SIM in Endo's study (tubular, villous) and Guelrud's study (villous, foveolar, cerebroid, deep linear). If none of those pit patterns was found, biopsy was taken from other present pit patterns. Because the endoscopic view is compromised due to bleeding when specimens are obtained, the number of areas selected for sampling was limited to two per patient to ensure that specimens corresponded to magnified images.

A control group consisted of patients with normal gastro-esophageal junctions proceeding with gastroscopy for reasons other than suspicion of Barrett's esophagus. In this group we thoroughly examined pit pattern in the region of cardia, and to rule out intestinal metaplasia we took biopsies from particular pit patterns following the similar principle as above, but without MB staining.

The study was approved by the Ethics Committee of the Medical University of Bialystok (clinical trial number 2PO5B 134 28). Patients signed informed consent before the examination. Images were recorded digitally.

To analyze relationships between nominal variables, Fisher's exact test or Fisher-Freeman-Halton's test were used. For contingency tables larger than $2 \times 2$ cells, 
standardized residuals were calculated to estimate contribution of individual cells into the result of the statistical test for the whole table [11]. The comparisons of quantitative variables' distributions were conducted using Mann-Whitney tests. The calculations were executed with Statsoft's Statistica 8.0 software, except for FisherFreeman-Halton tests, which were calculated with an application developed to implement an algorithm by Mehta and Patel [12]. To calculate standardized residuals Microsoft Excel 2003 was used.

All statistical hypotheses were verified at significance level equal to 0.05 .

\section{Results}

\section{Patient Characteristics}

Twenty-five patients, 18 men and 7 women with an average age of 57 years (range 33-77 years), were enrolled into the study. All patients had macroscopically visible and histologically proven gastric metaplasia in the esophagus. Eight patients had previously histologically proved SIM in the columnar lined esophagus. A control group consisted of ten patients with normal gastro-esophageal junction.

We took biopsies from 66 sites: 46 along Barrett's epithelium in the study group-average 1.84 per patientand 20 from epithelium below $\mathrm{Z}$ line in the control grouptwo per patient. Histological examination proved intestinal metaplasia in 14 out of 46 sites (30.4\%) in nine study patients $(36 \%)$. The rest of the biopsies revealed cardia type and gastric epithelium. No biopsy in the control group showed SIM. There were no statistical differences in age and sex between patients with and without SIM. Out of eight patients who had previously diagnosed SIM, in five it was also found in the present study and in three it was not.

There were 14 patients with the maximal length of the columnar epithelium below $3 \mathrm{~cm}$ (short segment Barrett's esophagus) and 11 patients with maximal length above $3 \mathrm{~cm}$ (long segment Barrett's esophagus). SIM was found in $63.6 \%$ of the patients with long segment Barrett's esophagus and in $14.3 \%$ of the patients with short Barrett esophagus $(P<0.05)$.

Hiatal hernia was diagnosed in 11 out of 25 patients. SIM in Barrett's esophagus was significantly more common among patients with hiatal hernia (8 patients, $72.7 \%$ ) than among patients without this condition ( 1 out of 14 patients, 7\%) $(P<0.001)$.

Methylene Blue Staining

Out of 46 biopsies in Barrett's patients, 29 were taken from methylene blue staining mucosa and ten of them proved
Table 1 Frequency of specialized intestinal metaplasia (SIM) in sites stained and not stained with methylene blue

\begin{tabular}{|c|c|c|c|c|}
\hline \multirow[t]{3}{*}{ SIM detection } & \multicolumn{4}{|c|}{ Methylene blue staining } \\
\hline & \multicolumn{2}{|c|}{ Negative $(N=17)$} & \multicolumn{2}{|c|}{ Positive $(N=29)$} \\
\hline & $n$ & $\%$ & $n$ & $\%$ \\
\hline $\operatorname{SIM}(-)$ & 13 & 85.7 & 19 & 66 \\
\hline SIM (+) & 4 & 14.3 & 10 & 34 \\
\hline
\end{tabular}

$N$ number of biopsies

Fisher's exact test: $P=0.198$ for association between positive methylene blue staining and SIM

SIM in histology (34\%). Seventeen biopsies were taken from places not staining with MB; histology proved SIM in four (14.3\%). There was no significant correlation between MB staining and diagnosis of SIM in histology. Sensitivity and specificity of MB staining in detecting SIM were 71.4 and $40.6 \%$. (Table 1 ).

\section{Pit-Pattern Evaluation Results}

Although we did not use the acetic acid enhancement recommended by Guelrud, we managed to qualify pit patterns in columnar lined esophagus in both scales in all cases. In nearly all patients and controls we found more than one type of pit pattern. Usually two to four types were intertwining like a patchwork, gradually changing one into another, with unclear borders. Tables 2 and 3 show the number of biopsies taken from the sites with a particular type of pit pattern in Endo's and Guelrud's classifications, respectively, and the incidence of SIM in those sites.

Besides the deep linear pattern found only in the study group, other pit patterns were identified both in the study group and in controls. Following study protocol, we first performed the biopsy of sites covered with pit patterns that, according to Endo and Guelrud, were related to SIM. There were significant differences between the study and the control group in the distribution of the types of pit patterns from which biopsy was taken $(P<0.05)$. This difference particularly concerned round pit patterns (Guelrud's scale) and small round pit patterns (Endo's scale), that were significantly more often subject of biopsy in the control group (respectively, $P<0.005$ and $P<0.05$ ). To some extent it can be concluded that in controls other types of pit patterns were found less often. In the study group two times more often than in the control group biopsy was taken from cerebroid (21.7 vs. 10\%) and from foveolar pit patterns (19.6 vs. $10 \%$ ), but the difference did not reach statistical significance.

Statistical analysis showed a significant relationship between the histological structure of Barrett's epithelium and pit patterns qualified in Gulerud's classification 
Table 2 Endo's classification: number of biopsies from sites with particular pit patterns and frequency of specialized intestinal metaplasia (SIM) in those pit patterns

\begin{tabular}{|c|c|c|c|c|c|}
\hline \multirow[t]{2}{*}{ Pit pattern } & \multicolumn{2}{|c|}{ Barrett's patients } & \multicolumn{2}{|c|}{ Control group } & \multirow{2}{*}{$\begin{array}{l}\text { Patients and controls } \\
\text { Percentage of biopsies } \\
\text { positive for SIM (\%) }\end{array}$} \\
\hline & $\begin{array}{l}\text { Number of } \\
\text { biopsies }\end{array}$ & $\begin{array}{l}\text { Number of biopsies } \\
\text { where SIM was proven }\end{array}$ & $\begin{array}{l}\text { Number of } \\
\text { biopsies }\end{array}$ & $\begin{array}{l}\text { Number of biopsies } \\
\text { where SIM was proven }\end{array}$ & \\
\hline Small round & 0 & 0 & 4 & 0 & 0 \\
\hline Straight & 2 & 0 & 0 & 0 & 0 \\
\hline Long oval & 5 & 2 & 2 & 0 & 28.5 \\
\hline Tubular & 16 & 3 & 6 & 0 & 13.6 \\
\hline Villous & 23 & 9 & 8 & 0 & 29.0 \\
\hline Together & 46 & 14 & 20 & 0 & 21.2 \\
\hline
\end{tabular}

Table 3 Guelrud's classification: number of biopsies from sites with particular pit patterns and frequency of specialized intestinal metaplasia (SIM) in those pit patterns

\begin{tabular}{|c|c|c|c|c|c|}
\hline \multirow[t]{2}{*}{ Pit pattern } & \multicolumn{2}{|c|}{ Barrett's patients } & \multicolumn{2}{|c|}{ Control group } & \multirow{2}{*}{$\begin{array}{l}\text { Patients and controls } \\
\text { Percentage of biopsies } \\
\text { positive for SIM (\%) }\end{array}$} \\
\hline & $\begin{array}{l}\text { Number of } \\
\text { biopsies }\end{array}$ & $\begin{array}{l}\text { Number of biopsies } \\
\text { where SIM was proven }\end{array}$ & $\begin{array}{l}\text { Number of } \\
\text { biopsies }\end{array}$ & $\begin{array}{l}\text { Number of biopsies } \\
\text { where SIM was proven }\end{array}$ & \\
\hline Round pit & 1 & 0 & 6 & 0 & 0 \\
\hline Thin linear & 1 & 0 & 0 & 0 & 0 \\
\hline Tubular pit & 6 & 1 & 2 & 0 & 12.5 \\
\hline Villous & 17 & 2 & 8 & 0 & 8 \\
\hline Foveolar & 9 & 6 & 2 & 0 & $54.5^{*}$ \\
\hline Cerebroid & 10 & 3 & 2 & 0 & 25 \\
\hline Deep linear & 2 & 2 & 0 & 0 & $100 *$ \\
\hline Together & 46 & 14 & 20 & 0 & 21.2 \\
\hline
\end{tabular}

* $P<0.05$ for association between particular pit patterns and SIM

$(P<0.005)$ but not in Endo's classification $(P=0.28)$. SIM did not coexist with round pit (Fig. 1) or thin linear patterns (Fig. 2) according to Guelrud's classification. Also SIM was not found at sites with small round (Fig. 1) and straight pit patterns (Fig. 2) according to Endo's classification. Those pit patterns were characteristic of gastric metaplasia. SIM was significantly frequent in regions covered with foveolar (Fig. 6) and deep linear pit patterns (Fig. 7) in Guelrud's classification (54 and 100\%, $P<0.05$ ). Tubular (Fig. 3), villous (Fig. 4), cerebroid (Fig. 5) pit patterns in Guelrud's classification and long oval (Fig. 8), tubular (Fig. 9), villous pit patterns (Fig. 10) in Endo's classification were less characteristic of SIM but they did not exclude this condition. Generally, SIM was found at sites with the same pit patterns as in the original studies of Endo and Guelrud, but less frequently (Table 4 and 5). Taking into consideration that, according to the study of Endo et al., tubular and villous pit patterns are characteristic of SIM, sensitivity and specificity for this classification in our study were respectively, 85.7 and $21.1 \%$. Similar to Endo's study, only $58 \%$ of sites covered by tubular and $56 \%$ of sites covered by villous pit patterns stained with methylene blue. Taking into consideration that, according to Guelrud's study, characteristics of SIM are deep linear, villous, foveolar and cerebroid pit patterns, sensitivity and specificity of this classification in our patients were respectively, 92.8 and $28.4 \%$.

No foci of dysplasia in Barrett's esophagus were fund. We observed no complications connected with the study.

\section{Discussion}

Intestinal metaplasia in columnar lined esophagus is the risk factor for esophageal adenocarcinoma [1]. SIM most often occurs focally and can't be distinguished from surrounding columnar epithelium with conventional endoscopy.

We found significant correlation between pit patterns evaluated according to Guelrud's scale and histology, which can potentially make biopsy more selective. However, simultaneous use of chromoscopy and optical magnification with assessment of mucosal surface did not significantly increase the frequency of SIM detection in the present study. The study design limited the number of biopsies to two per patient to prevent view blurring by blood and to ensure that specimens corresponded to magnified 


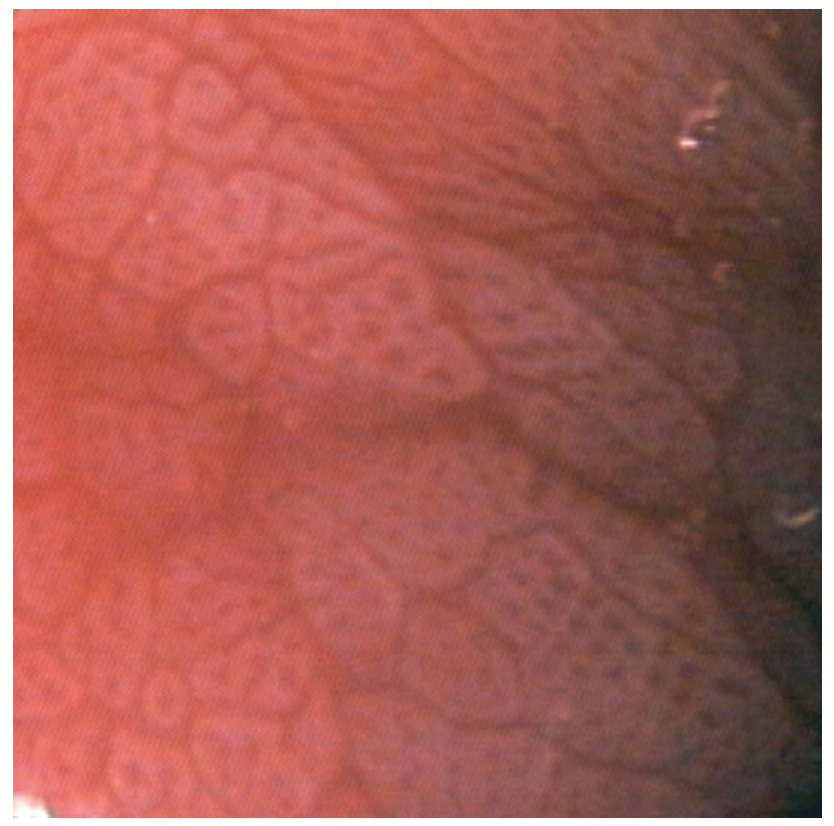

Fig. 1 Round pit pattern according to Guelrud's classification and small round pit pattern according to Endo's classification

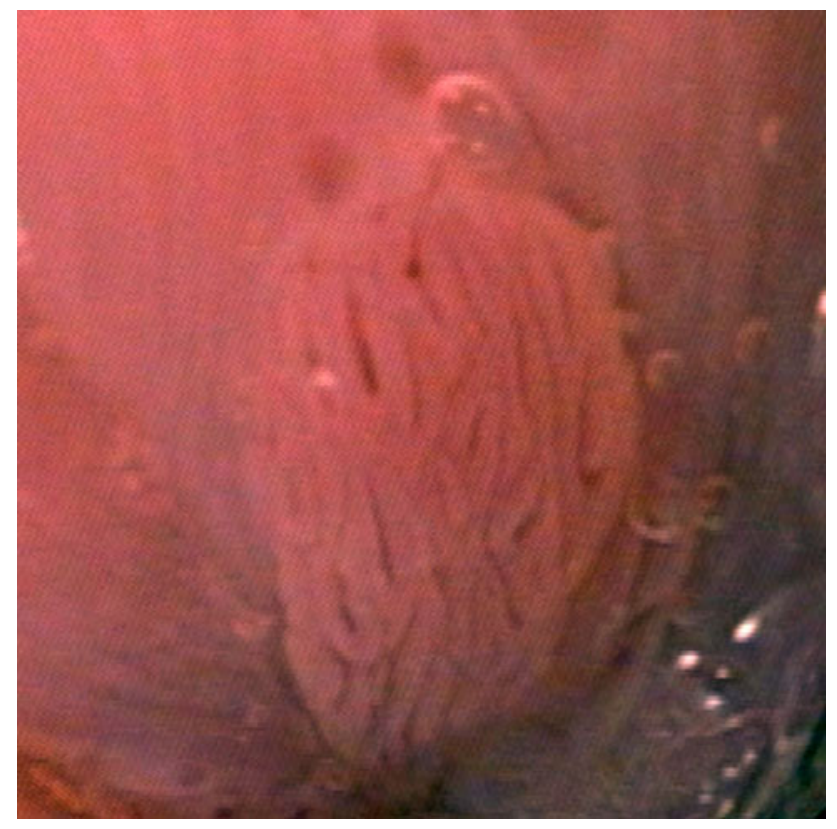

Fig. 2 Thin linear pit pattern according to Guelrud's classification and straight pit pattern according to Endo's classification

images. It facilitated precise evaluation of pit patterns in both scales and made "per biopsy" analysis more reliable. On the other hand reduction of the general number of biopsies probably resulted in a small percentage of patients with recognized SIM (36\%) in the present study and lowered sensitivity of the method in "per patient" analysis. According to Harrison et al. at least eight random biopsies should be taken to diagnose benign intestinal metaplasia

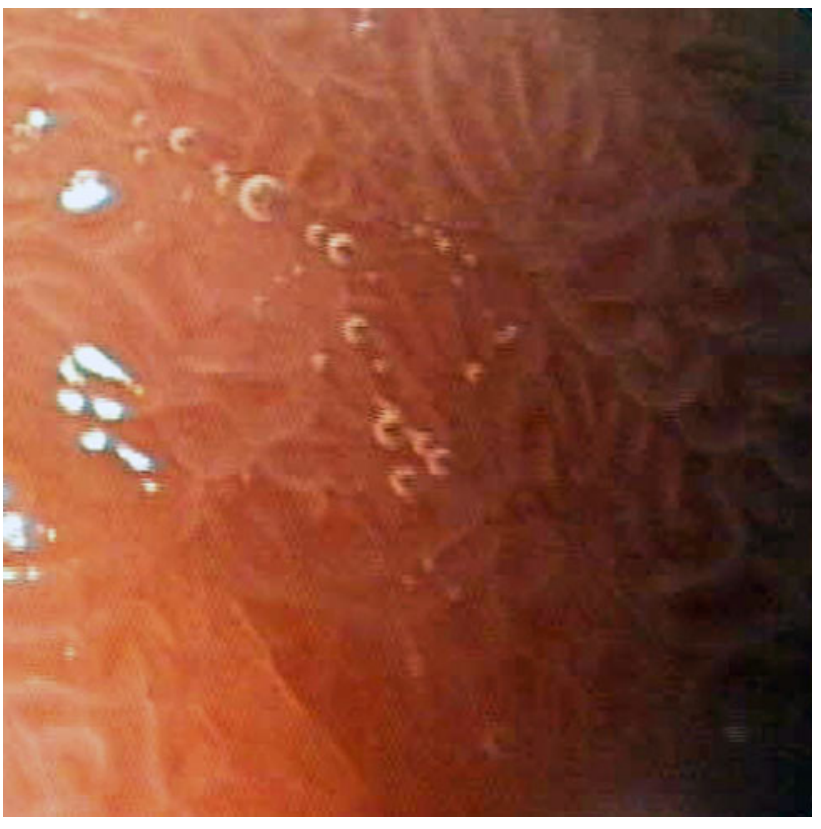

Fig. 3 Tubular pit pattern-Guelrud's classification

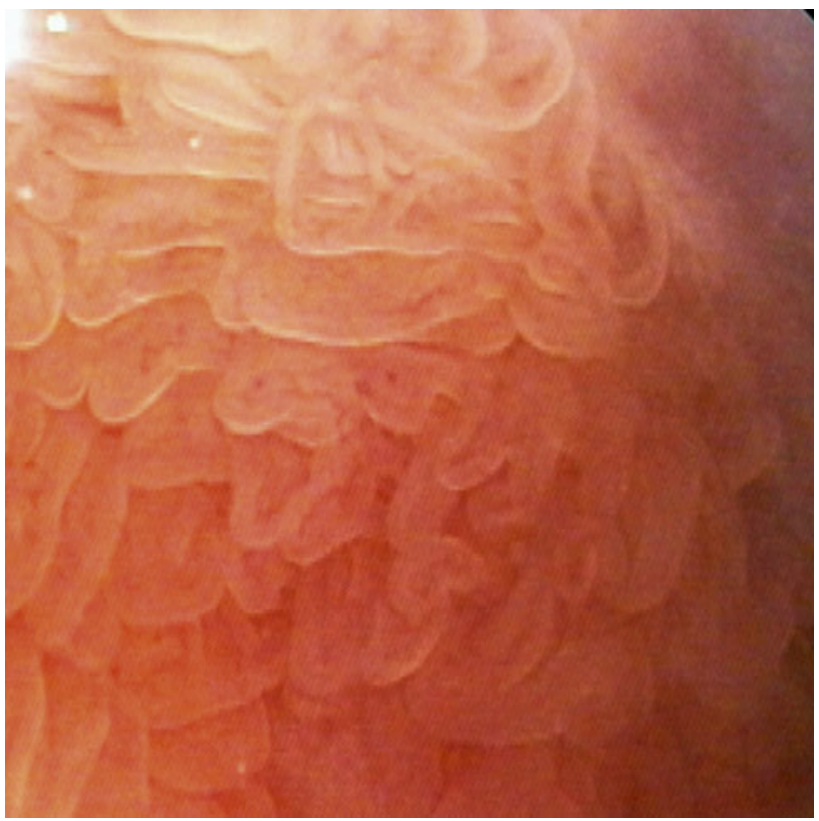

Fig. 4 Villous pit pattern-Guelrud's classification

[13]. In three patients with previously diagnosed SIM, this has not been confirmed in the present study. This finding suggests that taking few biopsies, even if they are aimed at stained sites with specific pit patterns, may be not enough to detect all sites with SIM. However, it cannot be ruled out that minor foci of SIM had been completely removed during previously taken biopsies. Another explanation is the possibility of histologic normalization of SIM after treatment with PPI, recently reported by Horwhat et al. [14]. 


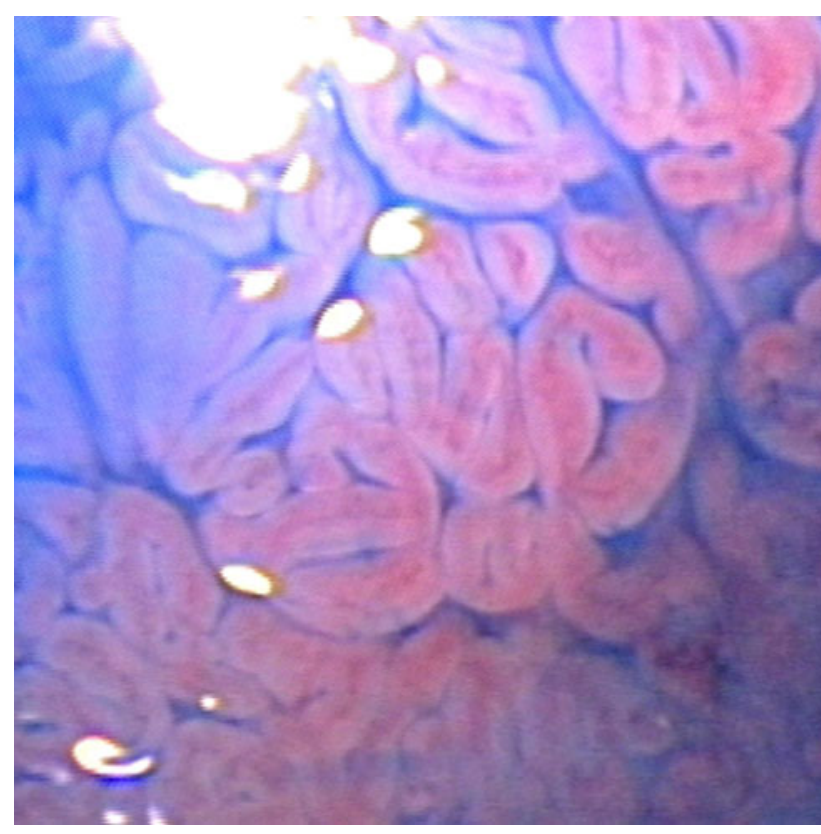

Fig. 5 Cerebroid pit pattern-Guelrud's classification

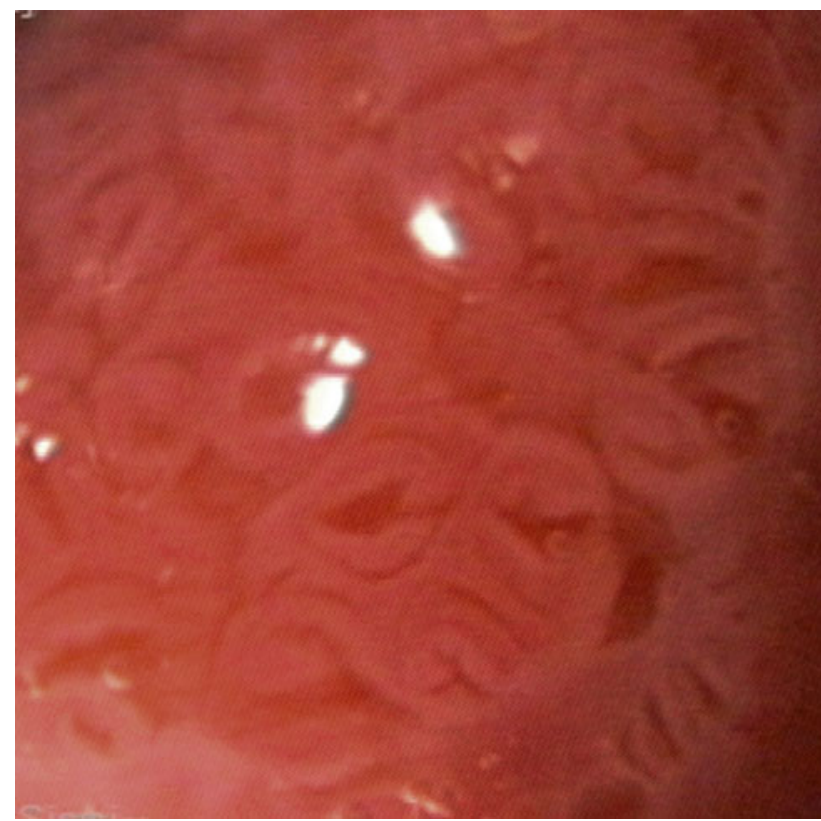

Fig. 6 Foveolar pit pattern-Guelrud's classification

In the present study SIM was significantly more frequent in patients with long-segment BE and hiatal hernia, which is in concordance with the previous observations [15]. We found the differences in frequency of SIM related to particular mucosal pit pattern types. In no case SIM coexisted with small round and straight pits, according to Endo's classification, or with round and thin linear pits according to Guelrud's classification. Those pit patterns were characteristic of gastric metaplasia. Similar results were

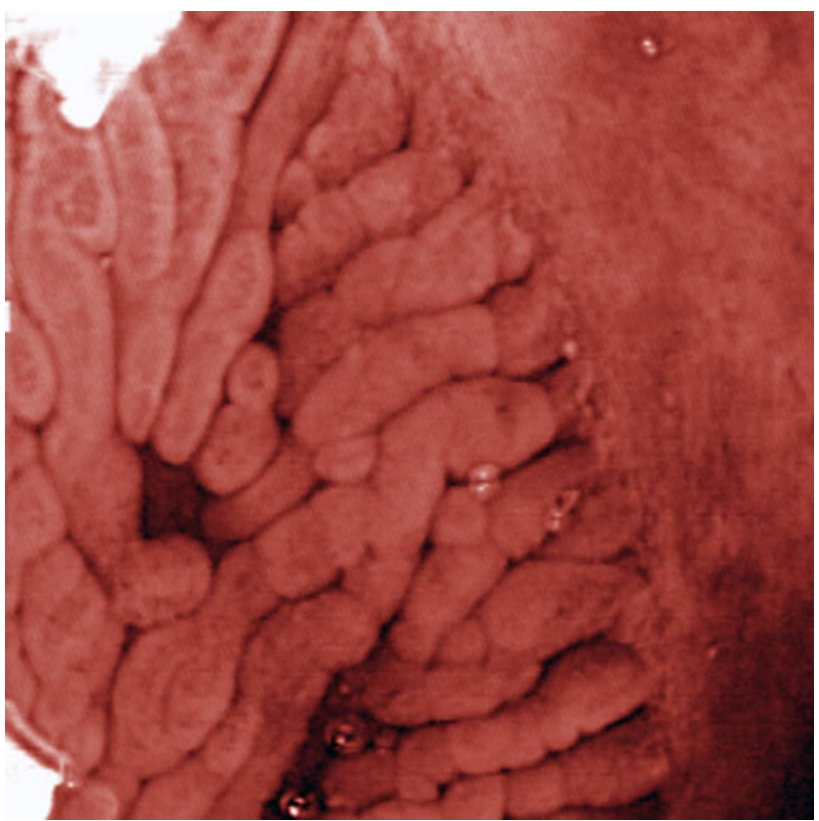

Fig. 7 Deep linear pit pattern—Guelrud's classification

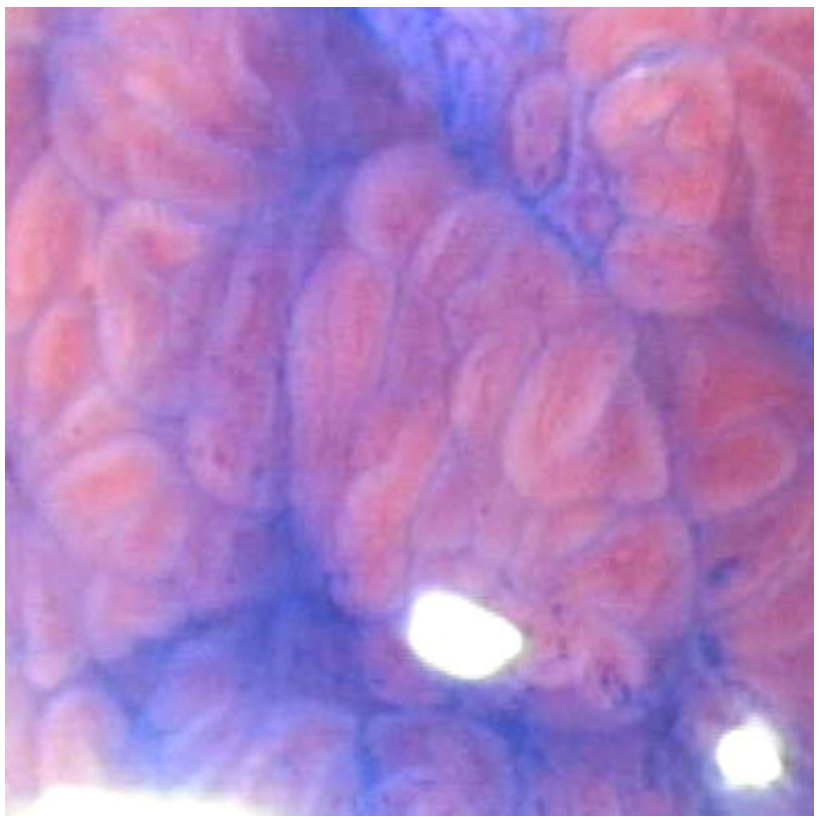

Fig. 8 Long oval pit pattern-Endo's classification

achieved by the authors of those classifications. Also in concord with Guelrud's study, we frequently found SIM in places with deep linear and foveolar pit patterns (respectively, in 100 and 54\%). It can be stated that these two types of surface structure are characteristic of SIM. On the contrary, we rarely found the coexistence of SIM with villous and cerebroid pit patterns according to Guelrud's classification-in our study it was respectively, 8 and 25\%, while in Guerlud's, respectively, 81.4 and $95.2 \%$. In 


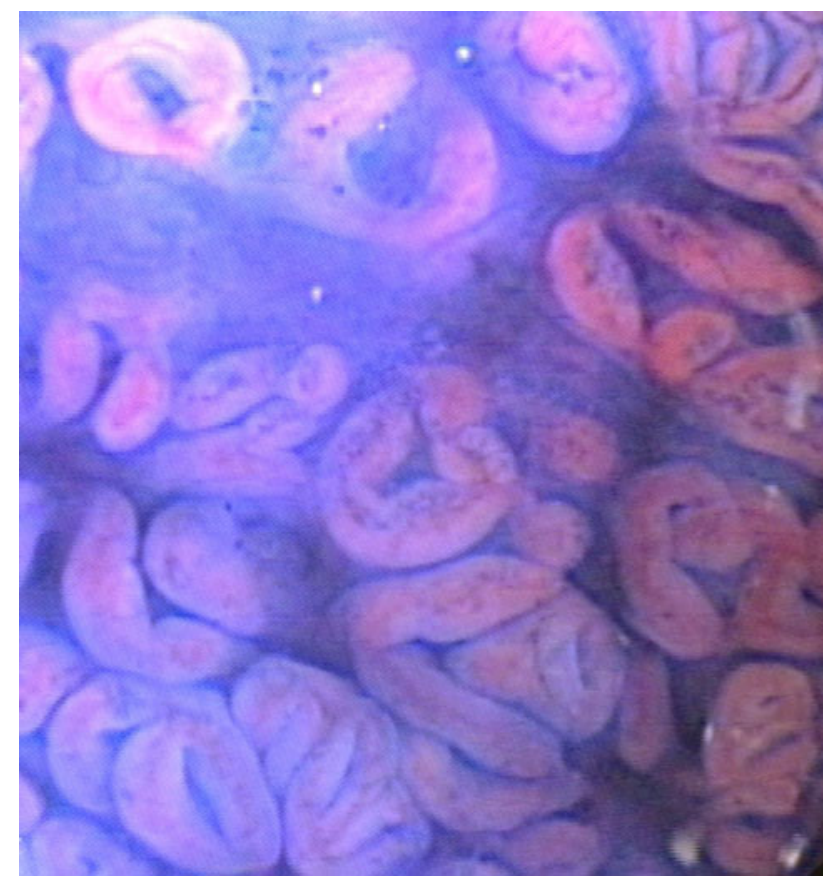

Fig. 9 Tubular pit pattern-Endo's classification

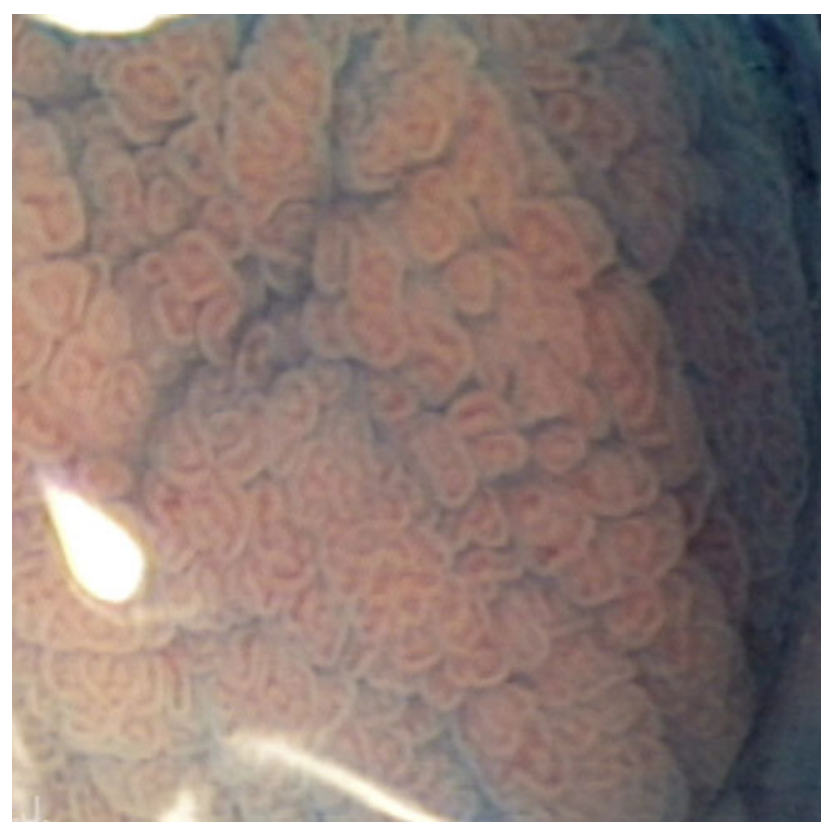

Fig. 10 Villous pit pattern-Endo's classification

comparison with Endo's study we rarely observed SIM in tubular (100 vs. $13.6 \%$ ) and villous pit patterns (100 vs. $29 \%$ ). Those pit patterns were not typical of SIM but did not rule out this condition. Besides deep linear pit pattern which was present only in patients, all other pit patterns were found both in patients and in the control group, which clearly diminished specificity of current findings.
To our knowledge, this study is so far the only one simultaneously evaluating mucosal surface structure both in Endo's and Guelrud's classification. Both classifications proved to have a high sensitivity but low specificity. Although we did not use acetic acid enhancement recommended by Guelrud, it was possible to qualify pit patterns to certain types in his classification. The precision of pit-pattern qualification with and without enhancement demands further evaluation. After staining with $\mathrm{MB}$, the dye is absorbed into the cells and specific mucosal surface structure becomes less visible, so it is easier to evaluate pit pattern before MB staining, independently from type of classification.

Both classifications were established on the basis of observation of a relatively small group of patients (Endo, 30 patients; Guelrud, 87 patients), and their high prognostic value in SIM detection has not been confirmed by other authors $[16,17]$. Neither of the two original studies evaluated pit patterns in any control group. Clinical utility of magnification endoscopy with pit-pattern evaluation is additionally limited by high interobserver variability of pit-pattern recognition [16]. In the present study we found examples of pit patterns difficult to classify to any type of known classification systems; therefore, those classifications seemed to be incomplete. It is possible that the elaboration of different classifications would improve the precision of SIM detection. In our opinion, it was easier to qualify pit patterns in Guelrud's than in Endo's classification, which can be attributed to more types discerned in the first one.

An important factor negatively influencing correlation of endoscopic pictures with histology is the difficulty in taking biopsy precisely from the place evaluated in magnification. While opening biopsy forceps, the endoscope is pushed away from the mucosa, which makes the constant observation in magnification impossible.

Canto et al. described a very high sensitivity (95\%) and specificity (97\%) of MB staining in detection of SIM, even without the use of magnification [5]. Such good results were not achieved in other studies, where the sensitivity of the method ranged from 72 to $75 \%$ and the specificity from 32 to $46 \%[18,19]$. In theory, magnification enables evaluation of sufficient wash-out of the dye and differentiation of truly stained places from those where the dye has been absorbed by mucus or fibrin covering erosions. Despite magnification, in our study MB staining had a very low specificity $(40.6 \%)$ and a moderate sensitivity $(71.4 \%)$ in SIM detection. Only $34 \%$ of MB stained sites were positive for SIM. Moreover, in four cases SIM was found in sites that did not stain with MB. According to Horwhat et al. [19], MB staining is not more accurate in evaluating SIM than fourquadrant biopsy from columnar mucosa in esophagus. Our results do not support the recommendation for using $\mathrm{MB}$ staining for SIM screening in columnar epithelium in 
Table 4 Relation between the pit pattern and existence of intestinal metaplasia-Endo's classification

\begin{tabular}{lcl}
\hline $\begin{array}{l}\text { Type of } \\
\text { pit pattern }\end{array}$ & \multicolumn{2}{l}{ Percentage of biopsies } \\
\cline { 2 - 3 } & $\begin{array}{l}\text { Endo's study [8] } \\
\text { (patients with BE) }(\%)\end{array}$ & $\begin{array}{l}\text { Present study (patients } \\
\text { with BE and control group) }(\%)\end{array}$ \\
\hline $\begin{array}{l}\text { Small } \\
\text { round }\end{array}$ & $6(n=17)$ & $0(n=4)$ \\
Straight & $0(n=5)$ & $0(n=2)$ \\
Long oval & $40(n=20)$ & $28.6(n=7)$ \\
Tubular & $100(n=8)$ & $13.9(n=22)$ \\
Villous & $100(n=2)$ & $29.0(n=31)$ \\
\hline
\end{tabular}

SIM specialized intestinal metaplasia, $B E$ Barrett's esophagus $n$ number of biopsies from particular type of pit pattern

Table 5 Relation between the pit pattern and existence of intestinal metaplasia-Gulerud's classification

\begin{tabular}{lcc}
\hline $\begin{array}{l}\text { Type of } \\
\text { pit pattern }\end{array}$ & \multicolumn{2}{l}{ Percentage of biopsies where SIM was confirmed } \\
\cline { 2 - 3 } & $\begin{array}{l}\text { Guelrud's study [9] } \\
\text { (patients with BE) }(\%)\end{array}$ & $\begin{array}{l}\text { Present study (patients with } \\
\text { BE and control group) }(\%)\end{array}$ \\
\hline Round pits & $0(n=87)$ & $0(n=7)$ \\
Thin linear & $10(n=9)$ & $0(n=1)$ \\
Tubular pits & $11(n=22)$ & $12.5(n=8)$ \\
Villous & $81.4(n=59)$ & $8(n=25)$ \\
Foveolar & $93.5(n=15)$ & $54.5(n=11)$ \\
Cerebroid & $95.2(n=21)$ & $25(n=12)$ \\
Deep linear & $100(n=9)$ & $100(n=2)$ \\
\hline
\end{tabular}

$S I M$ specialized intestinal metaplasia, $B E$ Barrett's esophagus

$n$ number of biopsies from particular type of pit pattern

esophagus. In comparison to $\mathrm{MB}$ staining, pit-pattern evaluation according to Guelrud's classification had a much higher sensitivity in detection of SIM in Barrett's esophagus (76.9 vs. $92.8 \%$ ), but a lower specificity (46.1 vs. $28.4 \%$ ).

With the procedure of mucolysis, MB staining and rinsing added approximately $4 \mathrm{~min}$ to the duration of gastroscopy. Time of evaluation of pit pattern under magnification differed from 2 to about 10 min and depended on length of columnar mucosa in the esophagus.

In this study, we found no sites with dysplasia, which may be attributed to relatively small number of patients or small number of biopsies.

According to the recommendations of the French Society of Digestive Endoscopy, none of new endoscopy techniques (chromoendoscopy, magnification, narrow band imaging, Fuji Intelligent Chromo Endoscopy) can replace multiple biopsies taken according to the Seattle protocol [20]. Despite proven association between pit pattern and histology, our data do not challenge those recommendations.
An interesting issue for future studies would be the potential advantage of taking numerous biopsies from regions selected with the use of magnification over random four-quadrant biopsies.

Taken together, there is association between surface pit patterns evaluated in Guelrud's scale and histology in Barrett's esophagus. SIM was a common finding in deep linear and foveolar pit patterns. Round pit and thin linear pit patterns were characteristic for gastric metaplasia. Low frequency of diagnosis of SIM in the present study can be attributed to small number of biopsies. Despite the potential advantage of evaluation of the mucosal surface under magnification and selection of the site of the biopsy according to pit pattern, we find no convincing data indicating that this protocol may replace multiple biopsies taken according to recommendations from Seattle for detection of SIM in Barrett's esophagus.

Acknowledgments This work was supported by the Polish State Committee for Scientific Research (KBN) grant 2PO5B 13428.

Open Access This article is distributed under the terms of the Creative Commons Attribution Noncommercial License which permits any noncommercial use, distribution, and reproduction in any medium, provided the original author(s) and source are credited.

\section{References}

1. Vakil N, van Zanten SV, Kahrilas P, Dent J, Jones R, Global Consensus Group. Montreal definition and classification of gastroesophageal reflux disease: a global evidence-based consensus. Am J Gastroenterol. 2006;101:1900-1920.

2. Pera M, Cameron AJ, Trastek VF, Carpenter HA, Zinsmeister AR. Increasing incidence of adenocarcinoma of the esophagus and esophagogastric junction. Gastroenterology. 1993;104:510-513.

3. Devesa SS, Blot WJ, Fraumeni JF Jr. Changing patterns in the incidence of esophageal and gastric carcinoma in the United States. Cancer. 1998;83:2049-2053.

4. Sampliner RE. Practice parameters committee of the American college of gastroenterology. Updated guidelines for the diagnosis, surveillance, and therapy of Barrett's esophagus. Am J Gastroenterol. 2002;97:1888-1895.

5. Canto MI, Setrakian S, Petras RE, Blades E, Chak A, Sivak MV Jr. Methylene blue selectively stains intestinal metaplasia in Barrett's esophagus. Gastrointest Endosc. 1996;44:1-7.

6. Dave U, Shousha S, Westaby D. Methylene blue staining: is it really useful in Barrett's esophagus? Gastrointest Endosc. 2001; 53:333-335.

7. Nelson DB, Block KP, Bosco JJ, et al. High resolution and highmagnification endoscopy: September 2000. Gastrointest Endosc. 2000;52:864-866.

8. Endo T, Awakawa T, Takahashi H, et al. Classification of Barrett's epithelium by magnifying endoscopy. Gastrointest Endosc. 2002;55:641-647.

9. Guelrud M, Ehrlich E. Endoscopic classification of Barrett's esophagus. Gastrointest Endosc. 2004;59:58-65.

10. Sharma P, Dent $\mathrm{J}$, Armstrong D, et al. The development and validation of an endoscopic grading system for Barrett's 
esophagus: the Prague C \& M criteria. Gastroenterology. 2006;131:1392-1399.

11. Sheskin D. Handbook of parametric and nonparametric statistical procedures. Washington: Chapman \& Hall/CRC.

12. Mehta CR, Patel NR. Algorithm 643: FEXACT: A FORTRAN subroutine for Fisher's exact test on unordered r x c contingency tables. ACM Trans Math Softw. 1986;12:154-161.

13. Harrison R, Perry I, Haddadin W, et al. Detection of intestinal metaplasia in Barrett's esophagus: an observational comparator study suggests the need for a minimum of eight biopsies. Am J Gastroenterol. 2007;102:1154-1161.

14. Horwhat JD. Normalization of intestinal metaplasia in the esophagus and esophagogastric junction: incidence and clinical data. Am J Gastroenterol. 2007;102:497-506.

15. Kerkhof M, Steyerberg EW, Kusters JG, Kuipers EJ, Siersema PD. Predicting presence of intestinal metaplasia and dysplasia in columnar-lined esophagus: a multivariate analysis. Endoscopy. 2007;39:772-778.

16. Meining A, Rösch T, Kiesslich R, Muders M, Sax F, Heldwein $\mathrm{W}$. Inter- and intra-observer variability of magnification chromoendoscopy for detecting specialized intestinal metaplasia at the gastroesophageal junction. Endoscopy. 2004;36:160-164.

17. Ferguson DD, DeVault KR, Krishna M, Loeb DS, Wolfsen HC, Wallace MB. Enhanced magnification-directed biopsies do not increase the detection of intestinal metaplasia in patients with GERD. Am J Gastroenterol. 2006;101:1611-1616.

18. Breyer HP, Silva De Barros SG, Maguilnik I, Edelweiss MI. Does methylene blue detect intestinal metaplasia in Barrett's esophagus? Gastrointest Endosc. 2003;57:505-509.

19. Horwhat JD, Maydonovitch CL, Ramos F, et al. A randomized comparison of methylene blue-directed biopsy versus conventional four-quadrant biopsy for the detection of intestinal metaplasia and dysplasia in patients with long-segment Barrett's esophagus. Am J Gastroenterol. 2008;103:546-554.

20. Boyer J, Laugier R, Chemali M, et al. French Society of Digestive Endoscopy SFED. French society of digestive endoscopy SFED guideline: monitoring of patients with Barrett's esophagus. Endoscopy. 2007;39:840-842. 